\title{
GSK-3 $\beta$ signaling determines autophagy activation in the breast tumor cell line MCF7 and inclusion formation in the non-tumor cell line MCF10A in response to proteasome inhibition
}

\author{
E Gavilán ${ }^{1,2,3}$, I Sánchez-Aguayo ${ }^{4}$, P Daza ${ }^{\star, 4}$ and D Ruano*,1,2
}

The ubiquitin-proteasome system and the autophagy-lysosome pathway are the two main mechanisms for eukaryotic intracellular protein degradation. Proteasome inhibitors are used for the treatment of some types of cancer, whereas autophagy seems to have a dual role in tumor cell survival and death. However, the relationship between both pathways has not been extensively studied in tumor cells. We have investigated both proteolytic systems in the human epithelial breast non-tumor cell line MCF10A and in the human epithelial breast tumor cell line MCF7. In basal condition, tumor cells showed a lower proteasome function but a higher autophagy activity when compared with MCF10A cells. Importantly, proteasome inhibition (PI) leads to different responses in both cell types. Tumor cells showed a dose-dependent glycogen synthase kinase-3 (GSK-3) $\beta$ inhibition, a huge increase in the expression of the transcription factor CHOP and an active processing of caspase-8. By contrast, MCF10A cells fully activated GSK-3 $\beta$ and showed a lower expression of both CHOP and processed caspase-8. These molecular differences were reflected in a dose-dependent autophagy activation and cell death in tumor cells, while non-tumor cells exhibited the formation of inclusion bodies and a decrease in the cell death rate. Importantly, the behavior of the MCF7 cells can be reproduced in MCF10A cells when GSK-3 $\beta$ and the proteasome were simultaneously inhibited. Under this situation, MCF10A cells strongly activated autophagy, showing minimal inclusion bodies, increased CHOP expression and cell death rate. These findings support GSK-3 $\beta$ signaling as a key mechanism in regulating autophagy activation or inclusion formation in human tumor or non-tumor breast cells, respectively, which may shed new light on breast cancer control.

Cell Death and Disease (2013) 4, e572; doi:10.1038/cddis.2013.95; published online 4 April 2013

Subject Category: Cancer

The ubiquitin-proteasome system (UPS) and the autophagylysosomal pathway are the two main systems for eukaryotic intracellular protein degradation. The 26S-proteasome is responsible for catalysis of the ATP-dependent degradation of poly-ubiquitinated proteins. ${ }^{1,2}$ In this sense, K48-ubiquitination is the canonical mark for proteins degraded by the proteasome. ${ }^{3}$ Moreover, in the presence of the pro-inflammatory cytokines interferon (IFN) $-\gamma$ or TNF- $\alpha$ cells can induce the synthesis of the immunoproteasome..$^{4-6}$ Unlike the UPS, the autophagy-lysosomal pathway is a catabolic process that can sequester and degrade cytoplasmic components through the lysosomes. Among the three types of autophagic degradation, ${ }^{7}$ macroautophagy (hereinafter referred to as autophagy) is the most important form of autophagy. It involves the formation of a double-membrane vesicle, called autophagosome, initiated by elongation of a de novo-formed membrane that seals on itself, sequestering cargo inside. Finally, the double-membrane vesicle fuses with lysosomes leading to autophagolysosome formation, where the cargo is degraded. Selective degradation of proteins is thought to be an exclusive function of the UPS, but a growing body of evidence claims that participation of autophagy may also be relevant. The identification of proteins that target proteins for autophagy degradation, or mediate cargo of phagosomes,

\footnotetext{
${ }^{1}$ Instituto de Biomedicina de Sevilla (IBIS)-Hospital Universitario Virgen del Rocío, Universidad de Sevilla, Sevilla, Spain; ${ }^{2}$ Departamento de Bioquímica y Biología Molecular. Facultad de Farmacia, Universidad de Sevilla, Sevilla, Spain; ${ }^{3}$ Centro Andaluz de Biología y Medicina Regenerativa (CABIMER), Sevilla, Spain and ${ }^{4}$ Departamento de Biología Celular, Facultad de Biología, Universidad de Sevilla, Avenida Reina Mercedes 6, Sevilla, Spain

*Corresponding author: P Daza, Departamento de Biología Celular, Facultad de Biología, Universidad de Sevilla, Avenida Reina Mercedes 6, 41012 Sevilla, Spain. Tel: + 34 954557042; Fax: + 34 954610261; E-mail: pdaza@us.es

or D Ruano, Instituto de Biomedicina de Sevilla, Hospital Universitario Virgen del Rocío, Universidad de Sevilla, Avd. Manuel Siurot s/n, 41013 Sevilla, Spain. Tel: + 34 955923054; Fax: + 34 954556598; E-mail: ruano@us.es

Keywords: autophagy; proteasome; GSK-3 $\beta$; breast cancer; protein aggregates; BAG proteins

Abbreviations: 3-MA, 3-methyladenine; Akt (PKB), protein kinase B; ATF4, activating transcription factor 4; Atg, autophagy-related genes; BAG, Bcl-2-associated athanogene; CHOP (GADD153), growth arrest and DNA damage-inducible gene 153; Cntr, C, control; CQ, chloroquine; DMSO, dimethyl sulfoxide; GAPDH, glyceraldehyde-3-phosphate dehydrogenase; GSK-3, glycogen synthase kinase-3; HER-2, human epidermal growth factor receptor 2; HLA, human leukocyte antigens; IFN- $\gamma$, interferon-gamma; LC3, microtubule-associated protein light chain 3; LiCl, lithium chloride; LMP2, proteasome (prosome, macropain) subunit, $\beta$-type 9 (large multifunctional peptidase 2); LMP7, proteasome (prosome, macropain) subunit, beta type 8 (large multifunctional peptidase 7; Lys, K, lisina; MCF, Michigan Cancer Foundation; MG132, MG, carbobenzoxy-leu-leuleucinal; PKC, protein kinase C; poly-Ub, poly-ubiquitinated; RT-PCR, reverse transcriptase-PCR; siRNA, si, small interfering RNA; TEM, transmission electron microscopy; UPR, unfolded protein response; UPS, ubiquitin-proteasome system

Received 06.12.12; revised 22.2.13; accepted 25.2.13; Edited by A Stephanou
} 
argues in favor of this idea. Destination of proteins for proteasome or autophagy degradation is regulated, at least in part, by the $\mathrm{Bcl}-2$-associated athanogen (BAG) proteins. The expression of BAG1 and BAG3 acts as a molecular switch mechanism determining whether proteins are degraded by the proteasome or autophagy, respectively. ${ }^{8,9}$ In this sense, BAG3 was found to act in concert with the ubiquitin-binding protein p62/SQSTM1 to increase autophagic activity. Moreover, p62/SQSTM1 binds also to LC3II- and K63-ubiquitinated proteins, putting together all the elements necessary for the autophagy activation and targeted cargo proteins. Here we focused on both the proteolytic systems in a non-tumor and in a tumor cell line. We show that tumor cells are more dependent on autophagy. Indeed, proteasome inhibition (PI) in MCF10A cells induced the formation of inclusion bodies with minor cell death, while increased basal autophagy in MCF7 cells, avoiding the formation of inclusion bodies, but raising the cell death rate. We provide solid evidence supporting that glycogen synthase kinase-3 (GSK-3) $\beta$ inhibition regulates autophagy activation induced by $\mathrm{PI}$ in the human breast cancer MCF7 cells.

\section{Results}

BAG1 and BAG3 are differentially expressed in MCF10A and MCF7 cells. As BAG-family proteins are involved in protein quality control, ${ }^{10,11,8}$ we characterized the expression of BAG1 and BAG3 in MCF7 and MCF10A cells, respectively. Among the four BAG1 isoforms, ${ }^{12}$ BAG1 $(\sim 36 \mathrm{kDa})$ and BAG1M ( 46 kDa) were mostly detected in MCF10A cells, whereas in MCF7 cells predominated BAG1, in a very low extent, BAG1M and BAG1L ( 50 kDa) (Figure 1a). On the other hand, basal expression of BAG3 was higher in MCF7 than in MCF10A cells, where it was practically absent $(P<0.05 ;$ Figure 1a). In consequence, the BAG3/BAG1 $(\sim 36 \mathrm{kDa})$ ratio was fourfold higher in tumor than in non-tumor cells.

Proteasome activity predominates in MCF10A and autophagy markers are increased in MCF7 cells. We further analyzed whether the different expression of BAG1 and BAG3 affected intracellular proteolytic systems. As shown in Figure 1b, MCF7 cells showed a significant reduction in the chymotrypsin-like activity of proteasome when compared with MCF10A cells $(P<0.05)$. This activity is catalyzed by both the constitutive $\beta 5$ and the inducible $\beta 5 \mathrm{i} / \mathrm{LMP} 7$ subunits. ${ }^{1,13}$ Both the subunits were expressed in MCF10A cells, but only the constitutive $\beta 5$ in MCF7 cells was detected (Figure 1c). The low expression of $\beta 5 \mathrm{i} / \mathrm{LMP} 7$ was not restricted to this subunit, but also to the $\beta 1 \mathrm{i} /$ LMP2 (Figure 1c). This could be consequence of the very low, if any, transcriptional expression of both subunits (Figure 1d). However, the structural subunit $\alpha 2$, present in both constitutive and immunoproteasome, was similarly expressed in both cell types, pointing to qualitative rather than quantitative differences in proteasomes between MCF7 and MCF10A cells. On the other hand, MCF7 cells showed a higher expression of several proteins related to the autophagy-lysosomal system. The autophagosome marker
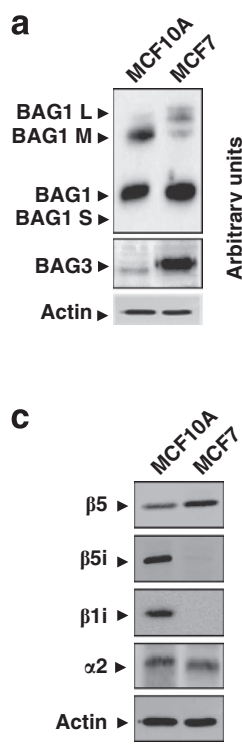

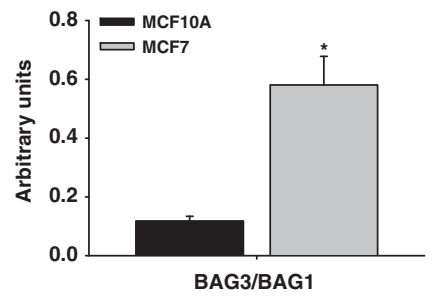

d
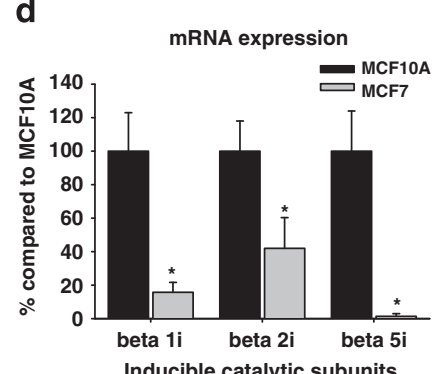

b
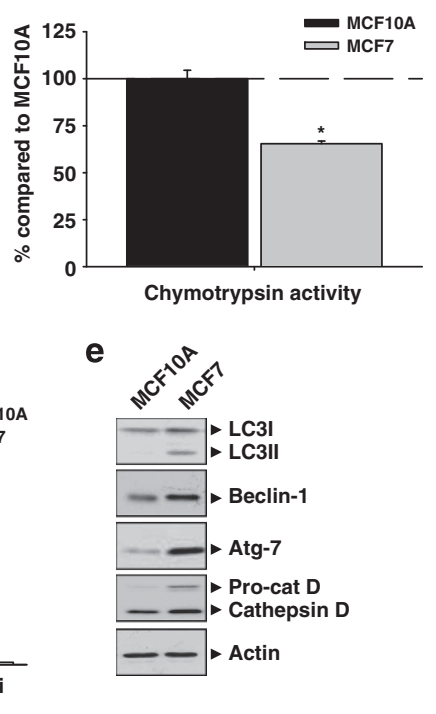

Figure 1 Proteasome and autophagic markers expressed in MCF10A and MCF7 cells in basal condition. (a) Different isoforms of the BAG1 protein were expressed in the MCF10A and MCF7 cells. In MCF10A cells BAG1 ( 36 kDa) and BAG1M ( $46 \mathrm{kDa})$ isoforms were detected, whereas BAG1 predominated in MCF7 cells. The BAG3 protein was observed in MCF7 but not in MCF10A cells. The graph shows the BAG3/BAG1 $\sim 36 \mathrm{kDa})$ ratio in both cell types. Data are presented as mean \pm S.D. of three independent experiments. (b) The chymotrypsin activity of proteasome was lower in MCF7 compared with MCF10A cells. Data are presented as mean \pm S.D. of four independent quantifications. (c) Constitutive and inducible proteasome catalytic subunits expressed in MCF10A and MCF7 cells. Note the low expression of inducible subunits in MCF7 cells. Experiments were repeated at least three times with similar results. (d) The mRNA expression of inducible catalytic subunits is downregulated in MCF7 cells compared with MCF10A cells. Data are presented as mean \pm S.D. of three independent experiments. MCF10A and MCF7 cells were analyzed in parallel. (e) Molecular markers of autophagy and cathepsin D expressed in MCF10A and MCF7 cells. Note the lower expression in MCF10A compared with MCF7 cells. Experiments were repeated at least three times with similar results. ${ }^{*} P<0.05$, significant differences compared with MCF10A cells 
a
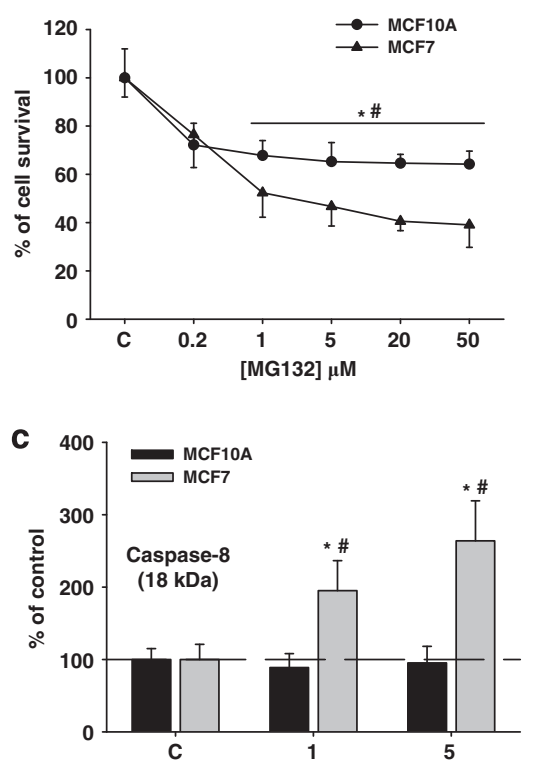

b
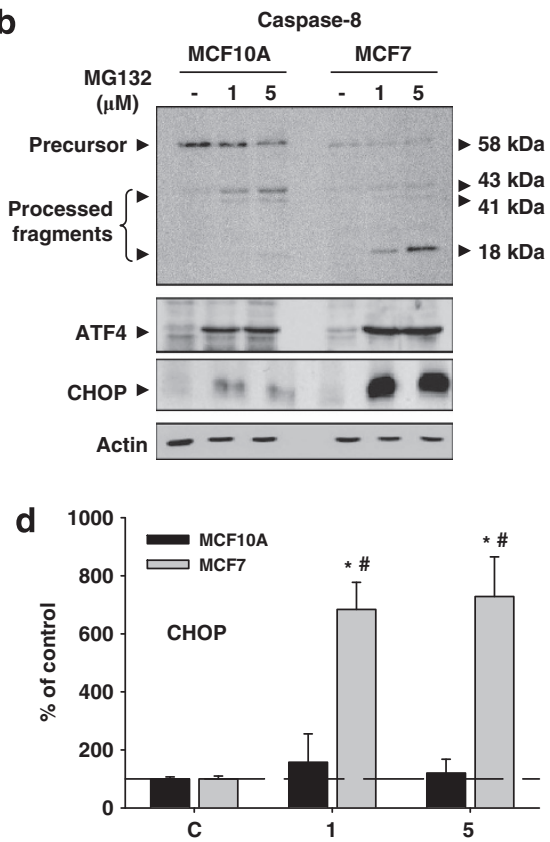

Figure 2 PI has a different effect on cell viability in MCF10A and MCF7 cells. (a) Graph representation of SRB assays performed in MCF10A and MCF7 cells using increasing doses of MG132. Note the higher sensitivity of MCF7 cells to PI. (b) Molecular analysis of caspase-8 (upper panel), ATF4 (middle panel) and CHOP (lower panel) expressed in MCF10A and MCF7 cells in control condition and $24 \mathrm{~h}$ after PI (1 and $5 \mu \mathrm{M}$ of MG132). Note the higher processing of caspase-8 and the strong expression of CHOP in MCF7 cells. (c and d) Graphs show quantification of active fragments of caspase-8 (18 kDa) and CHOP, respectively. Data are presented as mean \pm S.D. of three independent experiments done in parallel. ${ }^{*} P<0.05$, significant differences compared with control condition. ${ }^{\#} P<0.05$, significant differences compared with MCF10A cells

LC3II, in addition to proteins involved in the initiation of autophagy, such as Beclin-1 and Atg7, or the lysosomal enzyme cathepsin D, were more expressed in MCF7 than in MCF10A cells (Figure 1e). These data strongly indicate that intracellular proteolytic systems are altered in tumor MCF7 cells.

MCF7 are more vulnerable than MCF10A cells to cytotoxicity induced by acute PI. We next analyzed how $\mathrm{PI}$ affected cell survival. For that, proteasome activity was inhibited with MG132 for $24 \mathrm{~h}$, and then cell viability was analyzed by sulforhodamine B (SRB) assay. Cell viability was similarly affected with lower dose tested in both cell lines (Figure 2a). However, higher concentrations of MG132 significantly decreased the cell viability in MCF7 but not in MCF10A cells $(P<0.05)$, indicating that MCF7 cells were more sensitive to $\mathrm{PI}$. Then, we studied the expression of molecular markers corresponding to the extrinsic and intrinsic apoptotic pathways, in addition to markers of the unfolded protein response (UPR). Caspase-8 was highly processed in MCF7, but not in MCF10A cells (Figure $2 \mathrm{~b}$, upper panel and 2c). However, caspase-9 was not processed in any of both cell types (data not shown). By contrast, components of the UPR-PERK pathway such as the transcription factor activating transcription factor 4 (ATF4) was increased in both cell types, but the proapoptotic transcription factor CHOP, under control of ATF4, was strongly upregulated in MCF7, but weakly in MCF10A cells (Figure $2 \mathrm{~b}$, lower panel and $2 \mathrm{~d}$ ). Importantly, autophagy inhibition with 3-methyladenine mostly abolished CHOP expression (Figure $3 \mathrm{a}$ ), supporting that $\mathrm{CHOP}$ induction is more dependent on autophagy activation than on PI. Moreover, cell death induced by $\mathrm{PI}$ was almost abolished in Atg5 small interfering RNA (siRNA) MCF7 cells when compared with control siRNA MCF7 cells (Figure 3b), supporting that autophagy is a potential mechanism underlying cell death induced by PI in MCF7 cells.

PI induces autophagy activation in MCF7 but formation of inclusion bodies in MCF10A cells. We further investigated the cellular response induced by PI by performing a molecular analysis in both cell types. On the basis of previous data, we used $1 \mu \mathrm{M}$ and $5 \mu \mathrm{M}$ of $\mathrm{MG} 132$. We focused on the expression of BAG1 and BAG3 proteins. Regarding BAG1, we only analyzed the BAG1 isoform ( $\sim 36 \mathrm{kDa}$ ) because it was the most abundantly expressed in both cell types. In MCF10A, BAG1 expression decreased following $\mathrm{PI}(P<0.05)$, whereas in MCF7 cells it remained similar to the control condition (Figures $4 a$ and b). By contrast, BAG3 was massively upregulated in both cell types (Figures $4 \mathrm{a}$ and $\mathrm{c} ; P<0.05$ ), and consequently, the BAG3/ BAG1 ratio was significantly increased $(P<0.05)$. To test whether PI shifted towards autophagy degradation, as the BAG3/BAG1 ratio suggested, we analyzed the expression of two crucial proteins involved in the induction and execution of autophagy. The autophagosome marker LC3II was increased after $\mathrm{PI}$ in both cell types, but with different dynamics. In MCF10A, autophagosome marker LC3II only augmented with the higher dose of MG132 $(P<0.05)$, whereas in MCF7 cells it increased in a dose-dependent manner $(P<0.05)$. The expression of p62/SQSTM1, the protein acting as a cargo receptor for the degradation of 

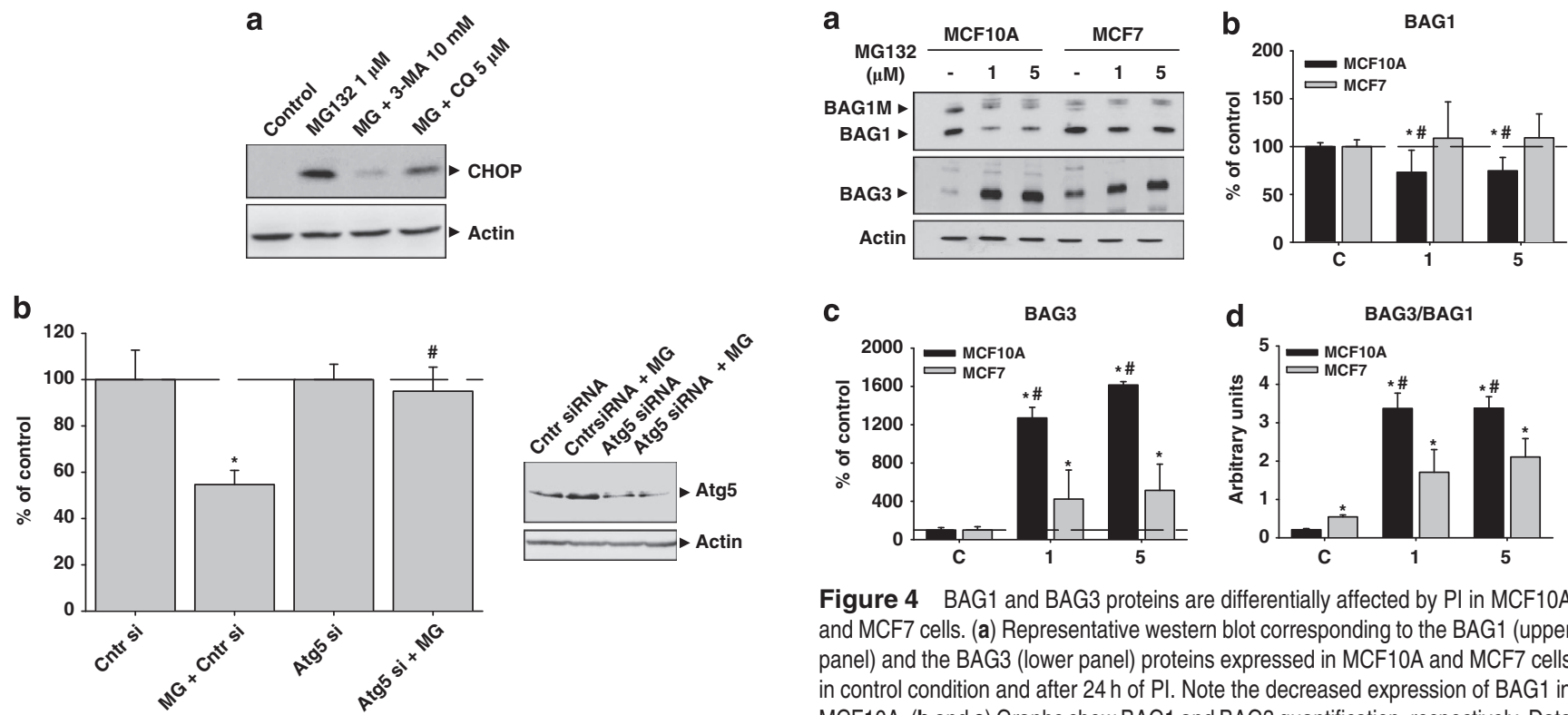

Figure 3 Effects of autophagy inhibition in MCF7 cells subjected to PI. (a) Autophagy initiation or autophagy completion were inhibited using $10 \mathrm{mM}$ of 3-methyladenine or $5 \mu \mathrm{M}$ of chloroquine, respectively, and the expression of the pro-apoptotic transcription factor CHOP was analyzed in MCF7 cells. Note the very low expression of CHOP in cells cotreated with MG132 and 3-MA. (b) Cell viability assay in Atg5 knockdown MCF7 cells. Control siRNA cells, or control siRNA cells treated with $1 \mu \mathrm{M}$ MG132 for $24 \mathrm{~h}$, or Atg5 siRNA cells, or Atg5 siRNA cells treated with $1 \mu \mathrm{M}$ MG132 for $24 \mathrm{~h}$, were subjected to SRB cell viability assay. Data are presented as mean \pm S.D. of four independent experiments done in parallel. ${ }^{*} P<0.05$, significant difference compared with control condition. ${ }^{\#} P<0.05$, significant difference compared with control MCF7 cells treated with MG132 $1 \mu \mathrm{M}$

ubiquitinated protein by autophagy, ${ }^{14}$ increased at both doses in MCF10A (Figures 5A and C; $P<0.05$ ), peaking at the lower dose, whereas in MCF7 cells it augmented in a dose-dependent manner (Figures $5 \mathrm{~A}$ and $\mathrm{C} ; P<0.05$ ). Thus, we speculate that MCF7 cells are more dependent on autophagy activity, whereas MCF10A cells are more dependent on proteasome degradation and need a stronger PI to activate autophagy. To prove directly this supposition, we performed an ultrastructural analysis using transmission electron microscopy (TEM). In control condition, we did not observe any relevant differences between both cell types (Figures 5Da and d). However, the morphological features induced by PI were completely different. On one hand, MCF10A cells accumulated electron-dense structures around the nucleus that increased in number and size in a dose-dependent manner (Figure 5Db). These aggregatedlike structures were membrane-free and were surrounded by numerous mitochondria (Figure 5Dc). The presence of multilamellar structures resembling autophagolysosomes was never observed in these cells. On the other hand, tumor cells MCF7 displayed a significant cytoplasmic vacuolization that increased also in a dose-dependent manner (Figure 5De). These cytoplasmic structures were different in size and showed a heterogeneous content that corresponded to digestion products (Figure 5Df). Importantly, the presence of inclusion bodies was never observed in MCF7 cells. To test whether these cytosolic vacuoles could correspond to autophagolysosomes, we used acridine c

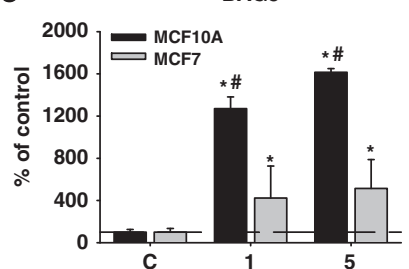

Figure 4 BAG1 and BAG3 proteins are differentially affected by $\mathrm{PI}$ in MCF10A and MCF7 cells. (a) Representative western blot corresponding to the BAG1 (upper panel) and the BAG3 (lower panel) proteins expressed in MCF10A and MCF7 cells in control condition and after $24 \mathrm{~h}$ of PI. Note the decreased expression of BAG1 in MCF10A. (b and c) Graphs show BAG1 and BAG3 quantification, respectively. Data are presented as mean \pm S.D. of three independent experiments done in parallel. (d) Graph representing the BAG3/BAG1 ratio in MCF10A and MCF7 cells in control condition and $24 \mathrm{~h}$ after $\mathrm{Pl}\left(1\right.$ and $5 \mu \mathrm{M}$ of MG132). ${ }^{*} P<0.05$, significant differences compared with control condition. ${ }^{\#} P<0.05$, significant differences compared with MCF10A cells

orange for acidic vesicle organelles detection. ${ }^{15}$ As shown in Supplementary Figure $1 \mathrm{~A}$, the number of acidic vesicles labeled with acridine orange increased in a dose-dependent manner in MCF7 but not in MCF10A cells, indicating a higher biogenesis of lysosomes and/or autophagolysosomes induced by $\mathrm{PI}$ in tumor cells. Moreover, to determine whether the accumulation of LC3II induced by PI in MCF7 cells is caused by stimulation of autophagy or inhibition of autophagic vesicle turnover, we performed both morphological and biochemical analysis. Ultrastructural analysis performed following PI (MG132 $1 \mu \mathrm{M}$ ) revealed the presence of features of autophagy activation such as abundant lysosomes, concentric double-membrane structures and cytosolic vacuoles containing digestion products (Supplementary Figure 1B). Moreover, PI in MCF7 cells in the absence or presence of chloroquine $5 \mu \mathrm{M}$ showed a higher LC3II accumulation in the presence of chloroquine, supporting autophagy flux (Supplementary Figure 1C). These results indicate that restoration of cellular homeostasis occurred in two different ways in both cell types: MCF7 overactivated basal autophagy, whereas MCF10A induced the formation of inclusion bodies.

PI promotes the accumulation of K63-ubiquitinated proteins, preferentially in MCF10A. Cellular inclusions are enriched in K63-ubiquitinated proteins. ${ }^{16-18}$ Thus, we investigated the topology of ubiquitin linkages in MCF10A and MCF7 cells. First, we quantified total poly-ubiquitinated proteins accumulated, following PI. As shown in Figures 6a and $b$, the accumulation of poly-ubiquitinated proteins was higher in MCF10A than in MCF7 cells. Interestingly, the linkage ubiquitin topology was little different in both the cell types. In MCF10A, PI preferentially accumulated 


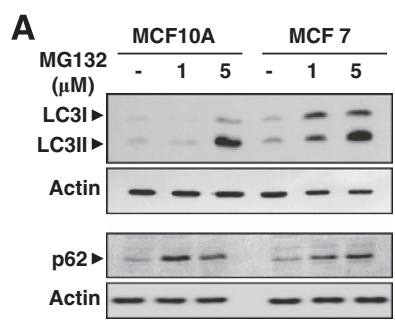

B

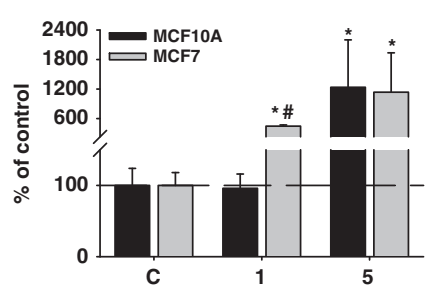

C

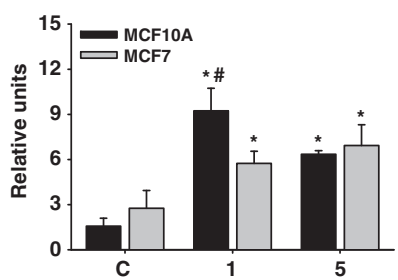

D CONTROL

$5 \mu \mathrm{M}$ MG132
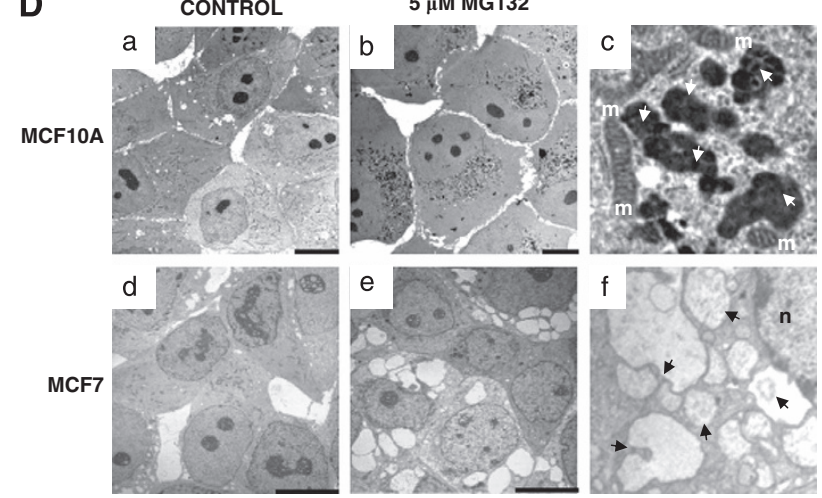

Figure 5 Molecular and ultrastructural analysis of autophagic markers induced by PI in MCF10A and MCF7 cells. (A) Representative western blot shown in MCF10A and MCF7 cells, in control condition and after $24 \mathrm{~h}$ of PI the expression of LC3I and LC3II (upper panel) and p62 (lower panel) proteins, respectively. Note the dose-dependent expression of LC3II and p62 in MCF7 cells. (B and C) Graph representation of data from western blots similar as shown in (a). Data are presented as mean \pm S.D. of four independent experiments done in parallel. (D) TEM of MCF10A and MCF7 cells in control condition ((a) and (d), respectively) and $24 \mathrm{~h}$ after PI (5 $\mu \mathrm{M}$ of MG132; (b and e)). Note the presence of inclusion bodies in MCF10A cells (b) and the cytoplasmic vacuolization in MCF7 cells. (e) In (c) and (f) are shown magnifications of inclusion bodies (white arrows) and autophagic vacuoles with digestion products inside (black arrows), respectively. $\mathrm{m}$, mitochondria; ${ }^{*} P<0.05$, significant differences compared with control condition; ${ }^{\#} P<0.05$, significant differences compared with MCF10A cells. Scale bar $10 \mu \mathrm{m}$
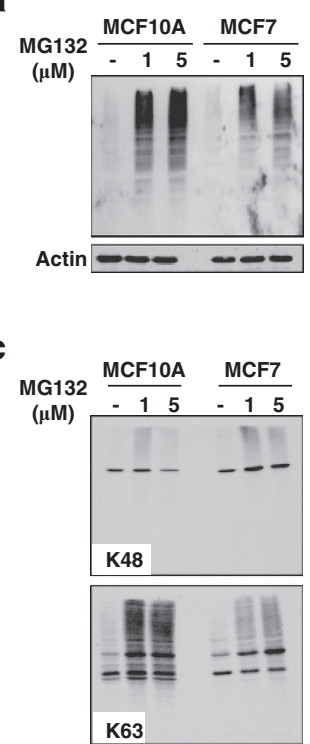

b

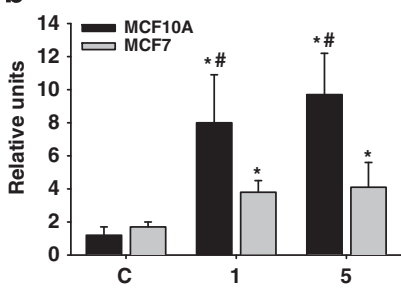

d

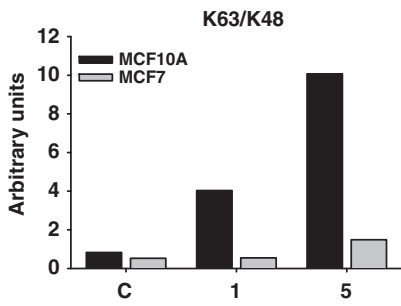

e
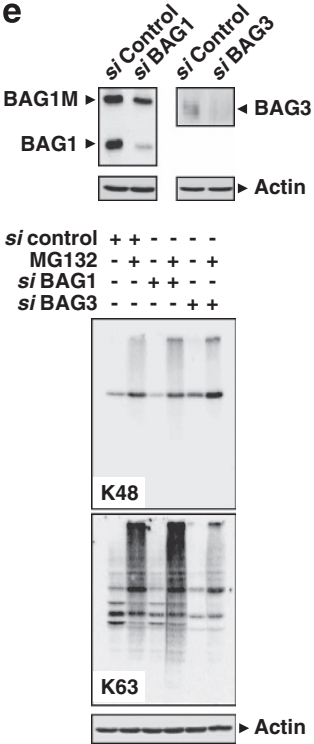

Figure 6 Profile of protein ubiquitination induced by PI in MCF10A and MCF7 cells. (a) Representative western blot of poly-ubiqutinated proteins in control condition and after $24 \mathrm{~h}$ of PI in MCF10A and MCF7 cells. (b) Graph representation of data from western blots similar as shown in (a). Data are presented as mean \pm S.D. of four independent experiments done in parallel. (c) Ubiquitinated proteins on K48 (upper panel) and K63 (lower panel) in control condition and $24 \mathrm{~h}$ after PI (1 and $5 \mu \mathrm{M}$ of MG132), in MCF10A and MCF7 cells. Note the accumulation of K63-ubiquitinated proteins in MCF10A cells, versus the dose-dependent increase in MCF7 cells. (d) In the graph is shown the K63/K48 ratio obtained from western blots similar as shown in (c). Experiments were done in parallel and repeated at least three times with similar results. (e) MCF10A cells were transfected with BAG1 siRNAs $(100 \mathrm{nM})$, BAG3 siRNAs $(100 \mathrm{nM})$ or negative control siRNAs $(100 \mathrm{nM})$ for $48 \mathrm{~h}$, and then subjected to PI $(1 \mu \mathrm{M}$ of MG132) for $24 \mathrm{~h}$. Controls of silencing are shown at the top. Ubiquitinated proteins on K48 (upper panel) and on K63 (lower panel) are shown. Note the PI-induced increase in the amount of K48 ubiquitinated proteins in cells transfected with BAG1 siRNAs and the strong decrease in the amount of ubiquinated proteins on K63 induced by PI in cells transfected with BAG3 siRNAs. ${ }^{*} P<0.05$, significant differences compared with control condition; ${ }^{\#} P<0.05$, significant differences compared with MCF10A cells 

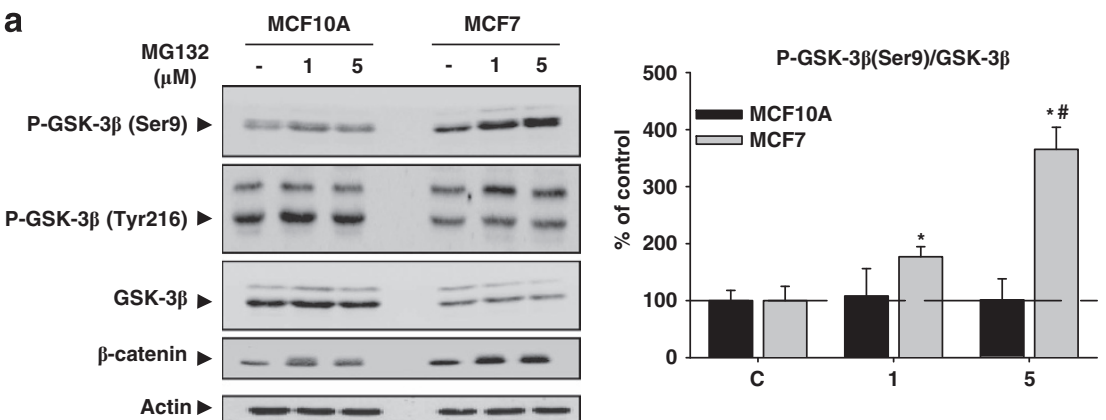

b
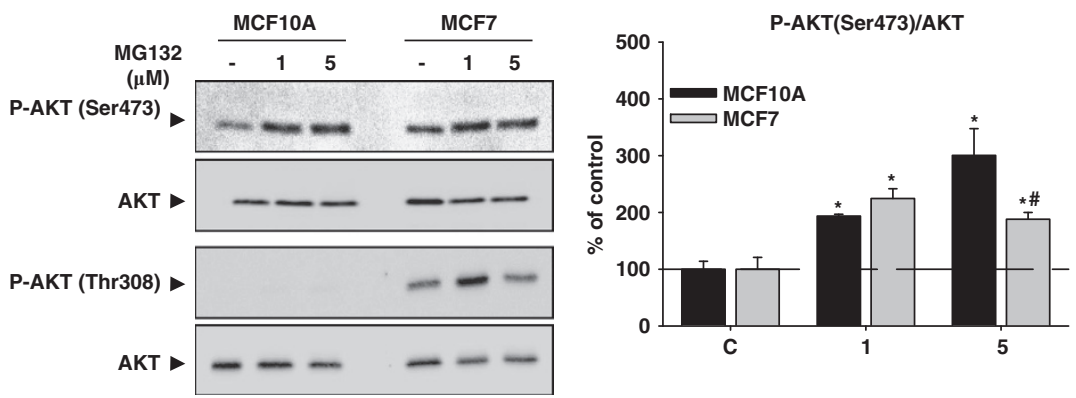

C
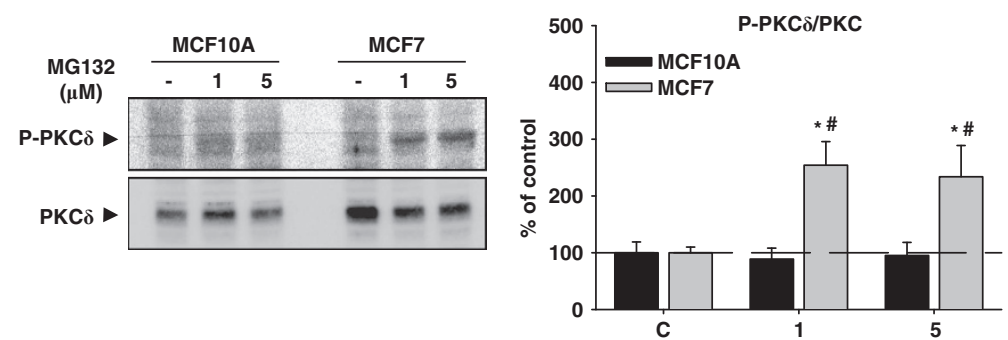

Figure 7 Akt/GSK-3 $\beta$ response induced by PI in MCF10A and MCF7 cells. (a) MCF10A and MCF7 cells were treated with MG132 (1 and $5 \mu \mathrm{M})$ for $24 \mathrm{~h}$, and then the amount of GSK-3 $\beta$ phosphorylated on Ser9 (upper panel) and on Tyr216 (middle panel) was analyzed. Note the dose-dependent increase of GSK-3 $\beta$ phosphorylated on Ser9 in MCF7 cells but not in MCF10A cells. The contrary was observed for GSK-3 $\beta$ phosphorylated on Tyr216. The amount of total GSK-3 $\beta$ was higher in MCF10A than in MCF7 cells, but PI did not modify its expression in any cell type. On the right is shown the quantification of the ratio between GSK-3 $\beta$ phosphorylated on Ser9 and GSK-3 $\beta$ in both cell types. The lower panel shows the $\beta$-catenin expression. Note the higher amount of $\beta$-catenin in MCF7 cells. (b) Similar as in (a), but analyzing Akt phosphorylated on Ser473 (upper panel) and on Thr308 (lower panel). Note the absence of Akt phosphorylated on Thr308 in MCF10A cells. On the right is shown the quantification of the ratio between Akt phosphorylated on Ser473 and Akt in both cell types. (c) Phosphorylated PKC $\delta$ and PKC $\delta$ expression in both cell types as well as quantification of the ratio between phosphorylated PKC $\delta$ and PKC $\delta$ (graph on the right). Note the higher basal expression of PKC $\delta$ and the dose-dependent increase of phosphorylated PKC $\delta$ in MCF7 cells versus the absence of it in MCF10A cells. ${ }^{*} P<0.05$, significant differences compared with control condition; ${ }^{\#} P<0.05$, significant differences compared with MCF10A cells

K63-ubiquitinated proteins, whereas MCF7 accumulated both K48- and K63-ubiquitinated proteins (Figure 6c). In consequence, the $\mathrm{K} 63 / \mathrm{K} 48$ ratio augmented in a dosedependent manner in MCF10A, but remained quite similar in MCF7 cells (Figure 6d). Importantly, ubiquitination profile was somehow regulated by BAG1 and BAG3 proteins. Indeed, PI in MCF10A cells transfected with BAG1 or BAG3 siRNAs slightly increased or severely decreased the content of K63-ubiquitinated proteins, respectively (Figure 6e). Thus, $\mathrm{PI}$ promotes the formation of protein inclusions enriched in K63-ubiquitinated proteins in MCF10A cells, whereas in MCF7 induces autophagic activity avoiding the formation of those inclusions.

GSK-3 $\beta$ is inhibited in MCF7 but fully activated in MCF10A cells, following PI. We next tried to identify additional pathways that could account for the different response induced by $\mathrm{PI}$ in both cell types. As GSK-3 $\beta$ inactivation has been demonstrated to participate in autophagy activation and cell death under stress situation, ${ }^{19}$ we focused our attention on the Akt/GSK-3 pathway. As shown in Figure 7a, PI increased in a dose-dependent manner GSK$3 \beta$ phosphorylation on Ser9 in MCF7, but not in MCF10A cells. Thus, GSK-3 $\beta$ was specifically inactivated in the tumor cells but remained active in MCF10A cells. To test whether this was related to the tumorigenic origin of cells, we used a transformed isogenic cell line of the MCF10A cells, named MCF10A-NeuT, which constitutively expresses an active form of the oncogene ErbB2/HER-2/NeuT. ${ }^{20} \mathrm{PI}$ produced both a higher GSK-3 $\beta$ phosphorylation on Ser9 and accumulation of LC3II in MCF10A-NeuT cells. This behavior was similar to that observed in MCF7 cells (Supplementary Figure 1D), indicating that differential regulation of GSK-3 $\beta$ by $\mathrm{PI}$ seems to be related with the tumorigenic origin of these cells. Moreover, MCF10A but not MCF7 cells augmented phosphorylation of GSK-3 $\beta$ on Tyr216, leading to a higher 
a
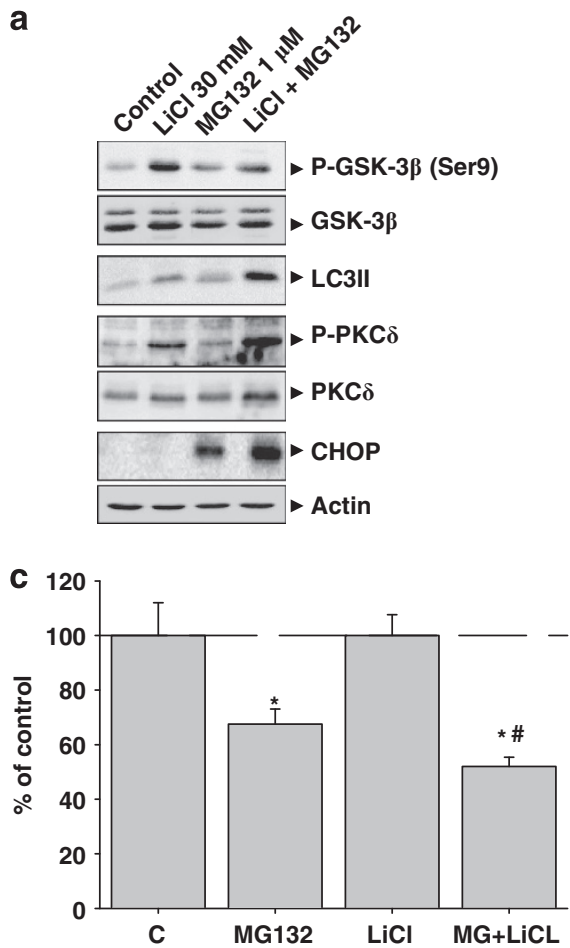

b

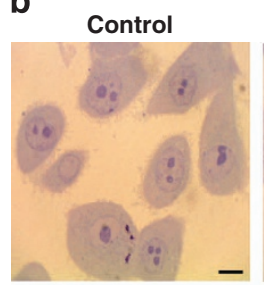

MG132 $1 \mu \mathrm{M}$

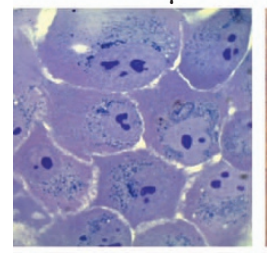

MG132 $1 \mu \mathrm{M}$

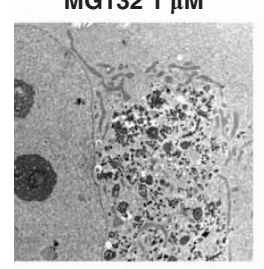

$\mathrm{LiCl} 30 \mathrm{mM}$

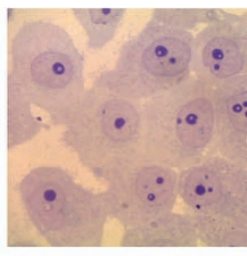

$\mathrm{LiCl}+\mathrm{MG} 132$

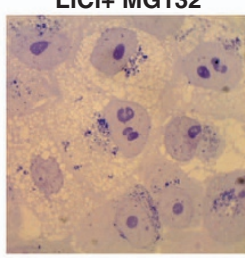

$\mathrm{LiCl}+\mathrm{MG} 1321 \mu \mathrm{M}$

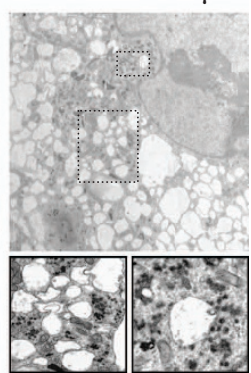

Figure 8 Cotreatment with LiCl and MG132 increases autophagy activity and rise up the rate of cellular death in MCF10A cells. (a) MCF10A cells were treated with MG132 $(1 \mu \mathrm{M}), \mathrm{LiCl}(30 \mathrm{mM})$ or both for $24 \mathrm{~h}$, and then different molecular markers were analyzed. Note the higher increase of LC3Il, phosphorylated PKC $\delta$ and CHOP in cotreated cells. (b) Upper panel; optical microscope photographs of control, LiCl, MG132 and cotreated MCF10A cells. Note the presence of inclusion bodies in proteasome inhibitortreated cells and the presence of cytoplasmic vacuoles in cotreated MCF10A cells; lower panel. Electron microscopic detection of inclusion bodies in proteasome inhibitortreated cells (left panel), and autophagic vacuoles in cotreated cells (right panel). (c) Cell viability assay in MCF10A cells. Untreated cells, or cells treated with $30 \mathrm{mM}$ LiCl, $1 \mu \mathrm{M}$ MG132 or both for $24 \mathrm{~h}$, were subjected to SRB cell viability assay. Data are presented as mean \pm S.D. of three independent experiments done in parallel. Scale bar $10 \mu \mathrm{m}$. ${ }^{*} P<0.05$, significant differences compared with control condition; ${ }^{\#} P<0.05$, significant differences compared with MG132 or LiCl treatments

activity of this kinase (Figure 7a, middle). The lower activity of GSK-3 $\beta$ was reflected in the accumulation of $\beta$-catenin, exclusively in MCF7 cells (Figure 7a, lower part). Interestingly, the behavior of GSK-3 $\alpha$ was also opposed in both cell types after PI (Figure 7a). Next, we analyzed both Akt and protein kinase $\mathrm{C}(\mathrm{PKC}) \delta$ phosphorylation, two kinases that phosphorylate GSK-3 $\beta$ on Ser9. ${ }^{21} \mathrm{PI}$ increased phosphorylation of Akt on Ser473 in both cell types, being the ratio of P-Akt/Akt higher in MCF10A than in MCF7 cells using MG132 $5 \mu \mathrm{M}$ (Figure 7b upper panel $P<0.05$ ). By contrast, the phosphorylation on Thr308 was exclusively detected in MCF7 cells in both, basal condition and following $\mathrm{PI}$ (Figure 7b lower panel). Similarly, PI induced phosphorylation of PKC $\delta$ in MCF7 but not in MCF10A cells (Figure 7c). These data indicate that $\mathrm{PI}$ induces an inverse regulation of signaling pathways involving GSK-3 $\beta$ in both cell lines.

Autophagy activation induced by $\mathrm{PI}$ is dependent on GSK-3 $\beta$ inactivation in MCF10A cells. To investigate whether GSK-3 $\beta$ inhibition and autophagy activation were causally related, we inhibited GSK-3 $\beta$ activity using lithium chloride ( $\mathrm{LiCl}$ ) and induced PI in MCF10A cells, which neither activated autophagy nor inhibited GSK-3 $\beta$. As shown in Figure 8a, treatment with $\mathrm{LiCl}$ sensitized MCF10A cells to $\mathrm{PI}$ (MG132 $1 \mu \mathrm{M}$; see Figure 5). As expected, LiCl (30 mM) increased Ser9 phosphorylation in GSK-3 $\beta$. Furthermore, the level of LC3II was slightly higher because of the transcriptional activation of the $L C 3$ gene (data not shown). A similar effect was obtained using the specific GSK-3 $\beta$ inhibitor VII (Supplementary Figure 1E). Moreover, LiCl augmented the phosphyorylation of PKC $\delta$ (Figure 8a), but not Akt phosphorylation (data not shown). Under this situation, PI strongly increased either the level of LC3II, the phosporylation of $\mathrm{PKC} \delta$ as well as $\mathrm{CHOP}$ expression. Cotreatment with $\mathrm{LiCl}$ and MG132 induced morphological changes in the cytoplasm of MCF10A cells, which were different to that observed in cells treated with MG132 alone. As previously shown, PI induced the formation of inclusion bodies without the evidence of autophagy activation (Figure 8b). However, the combination of $\mathrm{LiCl}$ and MG132 produced a high cytoplasmic vacuolization with minimal cytosolic aggregation (Figure $8 b$ ). Electron microscopy revealed the presence of inclusion bodies in MCF10A cells treated with MG132, but cytosolic vacuoles in cotreated MCF10A cells (Figure 8b lower panel). Some of these vacuoles were observed surrounding cytosolic aggregates (magnification in Figure 8b), showing heterogeneous content that may correspond to digestion products. These data strongly support that GSK-3 $\beta$ inhibition is necessary for autophagy activation. As autophagy inhibition decreased cell death induced by PI in MCF7 cells 
(Figure 3b), we investigated whether autophagy activation could increase cell death in MCF10A. As shown in Figure 8c, $\mathrm{PI}$ in the presence of $\mathrm{LiCl}$ significantly increased cell death compared with $\mathrm{PI}$ alone.

\section{Discussion}

We have characterized the two major cellular pathways involved in protein degradation in MCF10A and MCF7 cells. The study was carried out in both, basal and proteasome stress situations. In basal condition, MCF7 cells showed a lower proteasome activity that could be due, at least in part, to the absence of immunoproteasomes. The downregulation of immunoproteasome could benefit cancer cells by inhibiting antigen presentation, which in turn, could constitute an immune evasion strategy for some tumor types. The absence or reduced expression of immunoproteasomes has been previously described in other tumor cell lines. ${ }^{22-26}$ Thus, our results support the idea that immunoproteasome represents a promising prospect for certain tumors including breast cancer. The lowering of proteasome activity seems to be compensated by a higher autophagy activity. A growing body of evidence suggests that basal autophagy has a relevant homeostatic role in maintaining protein and organelle quality control, acting in parallel with the UPS to prevent accumulation of poly-ubiquitinated and aggregated proteins. ${ }^{7,27}$ Therefore, our results are in line with this idea. Although molecular links between both proteolytic systems are not completely understood, BAG1 and BAG3 have an important role in regulating both processes. ${ }^{28,8,9,11}$ BAG3 was overexpressed in MCF7 cells in basal condition, whereas its expression was residual in MCF10A cells. Importantly, differences in the proteolytic systems in basal condition determined the response to $\mathrm{PI}$ in both cell types. On one hand, cell mortality was higher in tumor cells than in non-tumor cells, and on the other hand the homeostatic response was completely different in both cell types. Biochemical data demonstrated that MCF7 cells did not modify the expression of BAG1 and coordinately upregulated, in a dose-dependent manner, the expression of BAG3, p62/SQSTM1 and LC3II. By contrast, MCF10A cells downregulated the expression of BAG1, but also upregulated BAG3, p62/SQSTM1 and LC3II, although with different dynamics and sensitivity to PI. These molecular differences were also reflected at the cellular level. Ultrastuctural analysis revealed that MCF7 cells showed profuse autophagy activation with none or minimal cytosolic inclusions, whereas MCF10A cells presented aggresome-like structures, without evidence of autophagy activation. Sequestration of aggregated proteins is classically considered a cellular response that occurs once the refolding capacity and degradation of soluble misfolded proteins are overpassed. ${ }^{29}$ Thus, our results indicated that tumor cells are more dependent on the autophagy, whereas non-tumor cells seem to be more dependent on the proteasome. Sequestration of misfolded proteins in MCF10A cells has a protective role in this context.

Autophagy is considered a non-selective degradative system, but growing evidence support the existence of selective autophagy that specifically targets protein aggregates for their clearance. ${ }^{30}$ In this sense, the ubiquitination pattern of proteins targeted for degradation could determine whether adapter proteins will bring them to the autophagosomes or to the proteasome. ${ }^{31,32,18}$ We demonstrated that dynamics of ubiquitinated proteins induced by $\mathrm{PI}$ was somehow different in both cell types. The K63/K48 ratio increased in a dose-dependent manner in MCF10A but not in MCF7 cells. Ubiquitination on K48 is considered a signal for proteasome degradation, whereas ubiquitination on K63 preferentially destines proteins to the autophagy-lysosomal pathway. ${ }^{3,31}$ However, it has also been described that K63-ubiquitinated proteins are more prone to form intracellular inclusions. ${ }^{17,18}$ On the other hand, the role of p62/SQSTM1 in the biogenesis of intracellular protein aggregates is well documented. This stress-regulated multiadaptor protein binds to both aggregated poly-ubiquitinated proteins, preferentially on K63 and LC3. ${ }^{33,14,16,31,34}$ Moreover, it is well established that p62/SQSTM1 regulates inclusion body formation and degradation by autophagy. ${ }^{35,36}$ Thus, we speculate that electron-dense structures induced by $\mathrm{PI}$ in MCF10A cells might agglutinate K63-ubiquitinated proteins, in addition to p62/SQSTM1, BAG3 and LC3. However, we cannot discard that other proteins showing different patterns of ubiquitination, or even non-ubiquitinated proteins, might take part in these intracellular inclusions. A similar situation could be operating in the tumor cells MCF7. However, because of the faster autophagy activation, probably due to the higher basal activity, protein accumulation and autophagy overactivation are better synchronized, avoiding protein accumulation. At this point, a relevant question is to know the molecular mechanisms underlying the different homeostatic responses in both cell types. We show strong evidence indicating that it somehow depends on GSK-3 $\beta$ activity. Indeed, GSK-3 $\beta$ was inversely regulated in both cell types following PI (inhibited in a dose-dependent manner in tumor cells and fully activated in non-tumor cells). Moreover, dose-dependent inactivation of GSK-3 $\beta$ was paralleled by dose-dependent activation of autophagy in MCF7 cells, and most importantly, autophagy activation in MCF10A cells only occurred when proteasome and GSK-3 $\beta$ were simultaneously inhibited. Under this situation, most of the molecular and morphological features induced by $\mathrm{PI}$ in MCF7 cells were reproduced in cotreated MCF10A cells such as, accumulation of LC3II, increased PKC $\delta$ phosphorylation, higher CHOP expression, extensive vacuolization with minor inclusion bodies and higher cell death. Thus, our results are in line with the recent data indicating that GSK- $3 \beta$ has a relevant role in regulating autophagy activity in tumor cells under stress situations. ${ }^{19,37}$ Under ER-stress, cells activate a signaling pathway called UPR that is mediated by the sensor proteins PERK, IRE $1 \alpha$ and ATF6, in order to mitigate the cellular stress. ${ }^{38}$ The UPR and autophagy activation are two linked phenomena. ${ }^{39,40}$ In particular, PERK pathway mediates transcriptional activation of LC3, Atg5 and Atg12 genes by the transcription factors ATF4 and CHOP. ${ }^{41-43}$ In this sense, we observed strong upregulation of ATF4 and mostly $\mathrm{CHOP}$ in MCF7, but not in MCF10A cells, following PI. However, in MCF10A subjected to both GSK-3 $\beta$ and PI, CHOP expression increased even more, similarly as observed in MCF7 cells. Finally, caspase-8 has also been linked to autophagy activation $^{44-47}$ and autophagy activity is necessary for 
cleavage of caspase- 8 induced by PI. ${ }^{48,19}$ Thus, the higher processing of caspase- 8 in MCF7 cells in both, basal- and proteasome stress situations might represent an additional factor that contributes to the higher basal autophagy activity in the tumor cell line MCF7.

Collectively, our findings strongly argue for the induction of autophagy as the main way to restore cell homeostasis under proteasome stress situation in the human breast cancer cells, MCF7. Moreover, we provide solid evidence supporting that efficient autophagy activation in response to $\mathrm{PI}$ is dependent on GSK-3 $\beta$. This finding is in line with a recent work, demonstrating that GSK-3 $\beta$ inhibition promoted lysosomal biogenesis and autophagy protein degradation. ${ }^{49}$ Finally, we also show that autophagy has an active role on cell death in the tumor cell line MCF7 subjected to proteasome stress. However, we cannot discard the possibility that autophagy activation in response to $\mathrm{PI}$ might be initially a prosurvival process in an attempt to keep cells alive, but with fatal collateral consequences.

\section{Materials and Methods}

Cells and culture conditions. The study was carried out in an $\mathrm{ER}+$ human epithelial breast cancer cell line, MCF7 and in a human epithelial-non tumorigenic breast cell line, MCF10A (American Type Culture Collection). MCF7 cells were cultured in DMEM/Ham's F12 (1/1) medium (PAA Laboratories, Piscataway, NJ, USA) supplemented with $10 \%$ (v/v) fetal bovine serum (FBS; Gibco, Alcobendas, Spain), $2 \mathrm{mM} \mathrm{L-glutamine,} 50 \mu \mathrm{g} / \mathrm{ml}$ streptomycin and $50 \mathrm{U} / \mathrm{ml}$ penicillin (Sigma-Aldrich, Madrid, Spain). The human mammary epithelial cells MCF10A and the transformed cell lines MCF10A-NeuT (oncogen ErbB2/HER-2/NeuT constitutively expressed) and MCF10A-pBabe (empty plasmid) were grown in DMEM/Ham's F12 (1/1) medium (PAA Laboratories) supplemented with $10 \%$ (v/v) horse serum (Gibco), $2 \mathrm{mM} \mathrm{L-glutamine,} 50 \mu \mathrm{g} / \mathrm{ml}$ streptomycin, $50 \mathrm{U} / \mathrm{ml}$ penicillin, $2.5 \mathrm{mg} / \mathrm{ml}$ insulin, $150 \mu \mathrm{g} / \mathrm{ml}$ cholera enterotoxin (Sigma-Aldrich), $2.5 \mathrm{mg} / \mathrm{ml}$ hydrocortisone and $50 \mu \mathrm{g} / \mathrm{ml}$ epidermal growth factor (Calbiochem, Billerica, MA, USA). Both cell lines were maintained at $37^{\circ} \mathrm{C}$ in a humidified atmosphere with $5 \% \mathrm{CO}_{2}$. Cells were routinely subcultured and they were always in exponential growth phase when used for experiments. Each experiment was independently performed at least in triplicate.

Treatments and drugs. Both cell lines were treated in parallel with the reversible proteasome inhibitor MG132 (Sigma-Aldrich), at doses indicated in the figures during $24 \mathrm{~h}$. Cells were also treated with $30 \mathrm{mM}$ of $\mathrm{LiCl}$ for $24 \mathrm{~h}$ (Sigma-Aldrich) or $20 \mu \mathrm{M}$ of GSK-3 $\beta$ inhibitor VII (Calbiochem) for GSK-3 $\beta$ inhibition. Treatments were carried out alone or in combination.

Proteasome activity assay. Chymotrypsin-like activity was determined using $50 \mu \mathrm{M}$ of Suc-Leu-Leu-Val-Tyr-aminomethylcoumarin (AMC; Sigma-Aldrich) as substrate, as previously described. ${ }^{50}$ Assay mixtures containing $10 \mu \mathrm{g}$ of protein, substrate and $50 \mathrm{mM}$ HEPES-KOH, $\mathrm{pH} 7.5$, was made up in a final volume of $100 \mu \mathrm{l}$. Measures were performed at $37^{\circ} \mathrm{C}$, by monitoring fluorescence emission (excitation wavelength $380 \mathrm{~nm}$, emission wavelength $460 \mathrm{~nm}$ ) on a Thermo Scientific Varioskan Flash Spectral Scanning Multimode Reader (software Scanlt, version 2.4.1, Alcobendas, Spain). The fluorescence emission was first determined 2 min after substrate incubation and then every 15 min during a total incubation period of $75 \mathrm{~min}$. The product formation was linear during this time. Triplicate assays were performed for MCF10A and MCF7 cells, and determinations were always performed in parallel. Activity was calculated by comparing the slopes of the line obtained by plotting fluorescence versus the time of incubation. Background activity was determined by addition of the proteasome inhibitor MG132 (Sigma-Aldrich), at a final concentration of $10 \mu \mathrm{M}$.

Sulforhodamine B assay. To assay cell viability, cells in exponential growth phase were harvested using trypsin-EDTA (Gibco), and resuspended in their respective media. Cells were seeded at a density of $5 \times 10^{3}$ cells $/ 100 \mu$ in a 96-well microtiter plate (Nunc, Roskilde, Denmark) and then allowed for $24 \mathrm{~h}$ to attach and grow. Then, they were incubated further for $24 \mathrm{~h}$ in the presence of proteasome inhibitor MG132. The concentration range tested $(200 \mathrm{nM}-50 \mu \mathrm{M})$ was prepared in a culture medium from a stock solution in DMSO (Sigma-Aldrich). Following the recommendations of the National Cancer Institute (Bethesda, MD, USA), the analysis of cytotoxic effects induced by MG132 was determined using a cell growth assay, the SRB (Sigma-Aldrich) assay, as previously described..$^{51,52}$ Briefly, $50 \mu \mathrm{l}$ per well of cold $50 \%$ trichloroacetic acid (TCA; final concentration $10 \%$ ) was added to the culture and incubated at $4{ }^{\circ} \mathrm{C}$ for $1 \mathrm{~h}$, to precipitate the proteins and fix the cells. The supernatant was then discarded, and the plates were washed five times with distilled water and air-dried. The cells were then stained with $100 \mu \mathrm{l}$ per well of $0.4 \%$ SRB dissolved in $1 \%$ acetic acid for $30 \mathrm{~min}$ at room temperature. Unbound SRB was removed by washing five times with $1 \%$ acetic acid, and then plates were air-dried. The stained protein was solubilized in $100 \mu \mathrm{l}$ per well of $10 \mathrm{mM}$ Tris Base, $\mathrm{pH}=8.7$ by shaking. The optical density was read at $515 \mathrm{~nm}$ using a microtiter plate reader (ELISA).

Acridine orange staining. As a marker of autophagy the cellular acidic compartments can be visualized by acridine orange staining. Cells were seeded on coverslips in the absence or in the presence of MG132 ( 1 or $5 \mu \mathrm{M}$, for $24 \mathrm{~h}$ ). Then cells were washed with PBS and incubated for $10 \mathrm{~min}$ with medium containing $0.1 \mu \mathrm{g} / \mathrm{ml}$ acridine orange (Molecular Probes, Alcobendas, Spain). The acridine orange was removed by washing coverslips with PBS (for 5 min three times). Fluorescent images were taken using a fluorescent microscope (Olympus BX61, Barcelona, Spain).

Western blotting. Immunoblots were done as previously described. ${ }^{50}$ Briefly, proteins were loaded on a 12 or $14 \%$ polyacrylamide gel for electrophoresis (SDS-PAGE; Bio-Rad, Alcobendas, Spain) and then transferred to a nitrocellulose membrane (Hybond-C Extra; Amersham, Barcelona, Spain). After blocking, membranes were incubated overnight at $4^{\circ} \mathrm{C}$, with the following primary antibodies: (i) rabbit polyclonal antibodies against: Akt, phospho-Akt(S473), phospho-Akt(T308), Atg5, Atg7, Beclin-1, Caspase-9, Cleaved Caspase-8, LC3B, phospho-GSK-3 $\beta($ S9) and SQSTM1/p62 (Cell Signaling, Danvers, MA, USA); BAG1 (c-16), Proteasome 20S alpha2 subunit $(\mathrm{H}-120$; Santa Cruz Biotech, Heidelberg, Germany). P-GSK-3 $\alpha(Y 279) / \beta(Y 216$; Invitrogen, Alcobendas, Spain); Ubiquitin (Dako, Glostrup, Denmark); Proteasome 20S alpha + beta, Proteasome $20 \mathrm{~S} \beta$ 5i/LMP7 and Proteasome 20S $\beta 1 \mathrm{i} / \mathrm{LMP2}$ (Abcam, Cambridge, UK); K48linkage Specific poly-ubiquitin Antibody (Cell Signaling) and K63-linkage Specific poly-ubiquitin (D7A11; Cell Signaling); (ii) mouse monoclonal antibodies against: $\beta$-actin (Sigma-Aldrich); CHOP (Cell Signaling); GSK 3-clone 4G-1E (Millipore, Madrid, Spain); ATF4 (Abcam) and (iii) goat polyclonal antibody against BAG3 (P17) (Santa Cruz Biotech). Then, membranes were incubated with the appropriate secondary antibody (Dako) horseradish peroxidase-conjugated, at a dilution of $1 /$ 10000 and developed using the ECL-plus detection method (Amersham) and the ImageQuant LAS 4000 MINI GOLD (GE Healthcare Life Sciences, Barcelona, Spain). For quantification, the optical density of individual bands was analyzed using PCBAS 2.08 software (Raytest Inc, Berlin, Germany), and the optical density of each band was normalized relative to the optical density of $\beta$-actin.

RNA extraction and reverse transcription. For PCR analysis, total RNA was extracted using the Tripure Isolation Reagent (Roche, Mannheim, Germany), according to the instructions of the manufacturer. The recovery of RNA was similar between MCF10A and MCF7 cells. Reverse transcription was performed using random hexamers primers exactly as previously described. ${ }^{53}$

Real-time reverse transcriptase-PCR. CDNAs were diluted in sterile water and used as template for the amplification by the PCR. Optimization and amplification of each specific gene product was performed using the ABI Prism 7000 sequence detector (Applied Biosystems, Barcelona, Spain) and TaqMan probes designed by Applied Biosystems, as previously described. ${ }^{50}$ The cDNA levels of the different cell types were determined using two different housekeepers (glyceraldehyde-3-phosphate dehydrogenase (GAPDH) and $\beta$-actin). The amplification of the housekeepers was done in parallel with the gene to be analyzed. Similar results were obtained using both housekeepers. Thus, the results were normalized using both $\beta$-actin and GAPDH expression. Threshold cycle $(\mathrm{Ct})$ values were calculated using the software supplied by Applied Biosystems.

Small interfering RNA. MCF10A and MCF7 cells were transfected during $48 \mathrm{~h}$ with $100 \mathrm{nM}$ of siRNA using Dharma-FECT 1 siRNA transfection reagent 
(Dharmacon, Madrid, Spain). MCF10A cells were transfected with BAG1 siRNA FlexiTube GeneSolution (GS573) or BAG3 siRNA FlexiTube GeneSolution (GS9531). MCF7 cells were transfected with Atg5 siRNA FlexiTube GeneSolution (GS9474). Control cells were transfected with AllStars Negative Control siRNA. All siRNA were purchased from Qiagen, Las Matas, Spain.

Transmission electron microscopy. Cell monolayers were fixed in $2.5 \%$ (v/v) glutaraldehyde in $0.1 \mathrm{M}$ sodium cacodylate $\mathrm{HCl}$ buffer $\mathrm{pH}=7.4$ for $1 \mathrm{~h}$ at $4{ }^{\circ} \mathrm{C}$. Cells were rinsed in cacodylate buffer twice and incubated for $1 \mathrm{~h}$ at $4{ }^{\circ} \mathrm{C}$ in $1 \%(\mathrm{v} / \mathrm{v}) \mathrm{OsO}_{4} / 1 \%(\mathrm{w} / \mathrm{v}) \mathrm{K}_{4} \mathrm{Fe}(\mathrm{CN})_{6}$ in cacodylate buffer $\mathrm{pH}=7.4$. Cells were rinsed again in cacodylate buffer and finally in distilled water. Then, cells were stained with $1 \%(\mathrm{w} / \mathrm{v})$ aqueous uranyl acetate for $2 \mathrm{~h}$ at $4{ }^{\circ} \mathrm{C}$. After washing with distilled water, they were dehydrated through increased graded ethanol series and embedded in Epon resin 812 (Sigma-Aldrich, Tres Cantos, Spain). Ultrathin sections were stained with lead citrate for $5 \mathrm{~min}$. Toluidine blue-stained $0.5 \mu \mathrm{m}$ semithin sections were used as control. All reagents were purchased from SigmaAldrich.

Statistical analysis. Data were expressed as mean \pm S.D. All our data fit significantly to a normal distribution according to a standardized Kurtosis test. The differences between groups were measured using a one-way ANOVA, followed by Tukey test. The significance was set at $95 \%$ confidence intervals. Significant differences are referenced as $P<0.05$ in the text. Statistical analysis was done using the statgraphics plus (v 3.1) program, Warrenton, VA, USA.

\section{Conflict of Interest}

The authors declare no conflict of interest.

Acknowledgements. We thank Remedios García Navarro for her technical assistance in TEM, Modesto Carballo Álvarez and Juan Luis Ribas Salgueiro from CITIUS for their technical assistance in proteasome activity meassurement and fluorescent microscopy. The MCF10A-NeuT and MCF10A-pBabe cell lines were provided by Dr. Abelardo López Rivas from CABIMER. This work was supported by Grant no. PS09/00848 and PI12/00445 (DR) from the Carlos III Health Institute, Spain. EG is supported by a contract from JA.

1. Jung T, Catalgol B, Grune T. The proteasomal system. Mol Aspects Med 2009; 30 191-296.

2. Rechsteiner $\mathrm{M}$, Hill CP. Mobilizing the proteolytic machine: cell biological roles of proteasome activators and inhibitors. Trends Cell Biol 2005; 15: 27-33.

3. Komander D. The emergin complexity of protein ubiquitination. Biochem Soc Trans 2009; 37: 937-953.

4. Gaczynska M, Rock KL, Goldberg AL. Gamma-interferon and expression of MHC genes regulate peptide hydrolysis by proteasomes. Nature 1993; 365: 264-267.

5. Preckel T, Fung-Leung WP, Cai Z, Vitiello A, Salter-Cid L, Winqvist $O$ et al. Impaired immunoproteasome assembly and immune responses in PA28-/- mice. Science 1999; 286: 2162-2165.

6. Rivett AJ, Bose S, Brooks P, Broadfoot KI. Regulation of proteasome complexes by gamma-interferon and phosphorylation. Biochimie 2001; 83: 363-366.

7. Mizushima N, Levine B, Cuervo AM, Klionsky DJ. Autophagy fights disease through cellular self-digestion. Nature 2008; 451: 1069-1075.

8. Gamerdinger M, Kaya AM, Wolfrum U, Clement AM, Behl C. BAG3 mediates chaperonebased aggresome-targeting and selective autophagy of misfolded proteins. EMBO rep 2011; 12: 149-156.

9. Gamerdinger M, Hajieva P, Kaya AM, Wolfrum U, Hart FU, Behl C. Protein quality control during aging involves recruitment of the macroautophagy pathway by BAG3. EMBO J 2009; 28: 889-901.

10. Takayama S, Reed JC. Molecular chaperone targeting and regulation by BAG family proteins. Nat Cell Biol 2001; 3: E237-E241.

11. Behl C. BAG3 and friends: co-chaperones in selective autophagy during aging and disease. Autophagy 2011; 7: 795-798.

12. Packham G, Brinimeli M, Cleveland JL. Mammalian cells express two 28. differently localized Bag-1 isoforms generated by alternative translation initiation. Biochem J 1997; 328: 807-813.

13. Groll M, Huber R. Inhibitors of the eukaryotic $20 \mathrm{~S}$ proteasome core particle: a structural approach. Biochim Biophys Acta 2004; 1695: 33-44.

14. Bjørkøy G, Lamark T, Brech A, Outzen H, Perander M, Øvervatn A et al. p62/SQSTM1 forms protein aggregates degraded by autophagy and has a protective effect on huntingtininduced cell death. J Cell Biol 2005; 171: 603-614.
15. Klionsky DJ, Cuervo AM, Seglen PO. Methods for monitoring autophagy from yeast to human. Autophagy 2007; 3: 181-206.

16. Pankiv S, Hoyvarde Clausen T, Lamark T, Brech A, Bruun JA et al. p62/SQSTM1 binds directly to Atg8/LC3 to facilitate degradation of ubiquitinated protein aggregates by autophagy. J Biol Chem 2007; 282: 24131-24145.

17. Tan JM, Wong ES, Kirkpatrick DS, Pletnikova O, Ko HS, Tay SP et al. Lysine 63-linked ubiquitination promotes the formation and autophagic clearance of protein inclusions associated with neurodegenerative diseases. Hum Mol Genet 2008; 17: 431-439.

18. Lim KL, Lim GG. K63-linked ubiquitination and neurodegeneration. Neurobiol Dis 2011; 43: 9-16.

19. Yang J, Takahashi Y, Cheng E, Liu J, Terranova PF, Zhao B et al. GSK-3 $\beta$ promotes cell survival by modulating Bif-1-dependent autophagy and cell death. J Cell Sci 2010; 123: 861-870.

20. Haenssen KK, Caldwell SA, Shahriari KS, Jackson SR, Whelan KA, Klein-Szanto AJ et al. ErbB2 requires integrin alpha5 for anoikis resistance via Src regulation of receptor activity in human mammary epithelial cells. J Cell Sci 2010; 123: 1373-1382.

21. Grimes CA, Jope RS. The multifaceted roles of glycogen synthase kinase 3 beta in cellular signaling. Prog Neurobiol 2001; 65: 391-426.

22. Johnsen A, France J, Sy MS, Harding CV. Down-regulation of the transporter for antigen presentation, proteasome subunits, and class I major histocompatibility complex in tumor cell lines. Cancer Res 1998; 58: 3660-3667.

23. Kageshita T, Hirai S, Ono T, Hicklin DJ, Ferrone S. Down-regulation of HLA class I antigen processing molecules in malignant melanoma: association with disease progression. Am J Pathol 1999; 154: 745-754.

24. Meidenbauer N, Zippelius A, Pittet MJ, Laumer M, Vogl S, Heymann J et al. High frequency of functionally active Melan-aspecific $T$ cells in a patient with progressive immunoproteasome-deficient melanoma. Cancer Res 2004; 64: 6319-6326.

25. Heink S, Fricke B, Ludwig D, Kloetzel PM, Krüger E. Tumor cell lines expressing the proteasome subunit isoform LMP7E1 exhibit immunoproteasome deficiency. Cancer Res 2006; 66: 649-652.

26. Fellerhoff B, Gu S, Laumbacher B, Nerlich AG, Weiss EH, Glas J et al. The LMP7-K allele of the immunoproteasome exhibits reduced transcript stability and predicts high risk of colon cancer. Cancer Res 2011; 71: 7145-7154.

27. Kraft C, Peter M, Hofmann K. Selective autophagy: ubiquitin-mediated recognition and beyond. Nat Cell Biol 2010; 12: 836-841.

28. Carra S, Seguin SJ, Landry J. HspB8 and Bag3: a new chaperone complex targeting misfolded proteins to macroautophagy. Autophagy 2008; 4: 237-239.

29. Tyedmers J, Mogk A, Bukau B. Cellular strategies for controlling protein aggregation. Nat Rev Mol Cell Biol 2010; 11: 777-788.

30. Kim PK, Hailey DW, Mullen RT, Lippincott-Schwartz J. Ubiquitin signals autophagic degradation of cytosolic proteins and peroxisomes. Proc Natl Acad Sci 2008; 105: 20567-20574.

31. Komatsu M, Waguri S, Koike M, Sou YS, Ueno T, Hara T et al. Homeostatic levels of p62 control cytoplasmic inclusion body formation in autophagy-deficient mice. Cell 2007; 131: 1149-1163.

32. Adhikari A, Chen ZJ. Diversity of polyubiquitin chains. Dev Cell 2009; 16: 485-486.

33. Seibenhener ML, Babu JR, Geetha T, Wong HC, Krishna NR, Wooten MW. Sequestosome $1 / p 62$ is a polyubiquitin chain binding protein involved in ubiquitin proteasome degradation. Mol Cell Biol 2004; 24: 8055-8068.

34. Olzmann JA, Li L, Chudaev MV, Chen J, Perez FA, Palmiter RD et al. Parkin-mediated K63-linked polyubiquitination targets misfolded DJ-1 to aggresomes via binding to HDAC6. J Cell Biol 2007; 178: 1025-1038.

35. Kirkin V, McEwan DG, Novak I, Dikic I. A role for ubiquitin in selective autophagy. Mol Cell 2009; 34: 259-269.

36. Johansen T, Lamark T. Selective autophagy mediated by autophagic adapter proteins. Autophagy 2011; 7: 279-296.

37. Choi $\mathrm{CH}$, Lee BH, Ahn SG, Oh SH. Proteasome inhibition-induced p38 MAPK/ERK signaling regulates autophagy and apoptosis through the dual phosphorylation of glycogen synthase kinase 3ß. Biochem Biophys Res Commun 2012; 418: 759-764.

38. Gavilán MP, Pintado C, Gavilán E, Jiménez S, Ríos RM, Vitorica J et al. Dysfunction of the unfolded protein response increases neurodegeneration in aged rat hippocampus following proteasome inhibition. Aging Cell 2009; 8: 654-665.

39. Milani M, Rzymski T, Mellor HR, Pike L, Bottini A, Generali D et al. The role of ATF4 stabilization and autophagy in resistance of breast cancer cells treated with Bortezomib. Cancer Res 2009; 69: 4415-4423.

40. Benbrook DM, Long A. Integration of autophagy, proteasomal degradation, unfolded protein response and apoptosis. Exp Oncol 2012; 34: 286-297.

41. Rouschop KM, Wouters BG. Regulation of autophagy through multiple independent hypoxic signaling pathways. Curr Mol Med 2009; 9: 417-424.

42. Rzymski T, Milani M, Pike L, Buffa F, Mellor HR, Winchester $L$ et al. Regulation of autophagy by ATF4 in response to severe hypoxia. Oncogene 2010; 29: 4424-4435.

43. Cook KL, Shajahan AN, Clarke R. Autophagy and endocrine resistance in breast cancer. Expert Rev Anticancer Ther 2011; 11: 1283-1294.

44. Boatright KM, Salvesen GS. Mechanisms of caspase activation. Curr Opin Cell Biol 2003; 15: $725-731$

45. Muñoz-Pinedo C, Ruiz-Ruiz C, Ruiz de Almodóvar C, Palacios C, López-Rivas A. Inhibition of glucose metabolism sensitizes tumor cells to death receptor-triggered apoptosis through 
enhancement of death-inducing signaling complex formation and apical procaspase-8 processing. J Biol Chem 2003; 278: 12759-12768.

46. Hughes MA, Harper N, Butterworth M, Cain K, Cohen GM, MacFarlane M. Reconstitution of the death-inducing signaling complex reveals a substrate switch that determines CD95-mediated death or survival. Mol Cell 2009; 35: 265-279.

47. Lee JS, Li Q, Lee JY, Lee SH, Jeong JH, Lee HR et al. FLIP mediated autophagy regulation in cell death control. Nat Cell Biol 2009; 11: 1355-1362.

48. Laussmann MA, Passante E, Düssmann H, Rauen JA, Würstle ML, Delgado ME et al. Proteasome inhibition can induce an autophagy dependent apical activation of caspase-8. Cell Death Differ 2011; 18: 1584-1597.

49. Parr C, Carzaniga R, Gentleman SM, Van Leuven F, Walter J, Sastre M. Glycogen synthase kinase 3 inhibition promotes lysosomal biogenesis and autophagic degradation of the amyloid- $\beta$ precursor protein. Mol Cell Biol 2012; 32: 4410-4418.

50. Gavilán MP, Pintado C, Gavilán E, García-Cuervo LM, Castaño A, Ríos RM et al. Age-related differences in the dynamics of hippocampal proteasome recovery. J Neurochem 2012; 123: 635-644.
51. Skehan P, Storeng R, Scudiero D, Monks A, McMahon J, Vistica D et al. New colorimetric cytotoxicity assay for anticancer-drug screening. J Natl Cancer Inst 1990; 82: 1107-1112.

52. Keepers YP, Pizao PE, Peters GJ, van Ark-Otte J, Winograd B, Pinedo HM. Comparison of the sulforhodamine $B$ protein and tetrazolium (MTT) assays for in vitro chemosensitivity testing. Eur J Cancer 1991; 27: 897-900.

53. Gavilán MP, Pintado C, Gavilán E, Jiménez S, Ríos RM, Vitorica J et al. Dysfunction of the unfolded protein response increases neurodegeneration in aged rat hippocampus following proteasome inhibition. Aging Cell 2009; 8: 654-665.

cc) $\odot$ Cell Death and Disease is an open-access journal BY NC ND published by Nature Publishing Group. This work is licensed under a Creative Commons Attribution-NonCommercialNoDerivs 3.0 Unported License. To view a copy of this license, visit http://creativecommons.org/licenses/by-nc-nd/3.0/

Supplementary Information accompanies this paper on Cell Death and Disease website (http://www.nature.com/cddis) 